\title{
Intravenous flurbiprofen for post-thymectomy pain relief in patients with myasthenia gravis
}

\author{
Chunhua Su${ }^{1 \dagger}$, Yihua Su${ }^{2 \dagger}$, Chiu-Wen $\mathrm{Chou}^{3}$, Weibing Liư ${ }^{4}$, Jianyong Zou', Honghe Luo ${ }^{1 *}$ \\ and Zhenguang Chen ${ }^{1,5^{*}}$
}

\begin{abstract}
Background: Post-thymectomy pain in myasthenia gravis (MG) patients can inhibit breathing and coughing. Inappropriate usage of analgesics may exacerbate respiratory inhibition and even cause myasthenic crisis. Flurbiprofen is a non-steroidal anti-inflammatory drug (NSAID) that is commonly used to control moderate postoperative pain and is not associated with respiratory inhibition. We hypothesized that flurbiprofen may provide post-thymectomy pain relief without increasing the risk of complications in MG patients.
\end{abstract}

Methods: Two hundred MG patients underwent extended thymectomy from March 2006 to December 2010 and were randomly allocated to a flurbiprofen group (110 patients, $50 \mathrm{mg}$ intravenous flurbiprofen axetil) or a control group (90 patients, $100 \mathrm{mg}$ intramuscular tramadol) as postoperative analgesia. Visual analog scale (VAS) pain score, heart rate, blood pressure, respiratory rate, pulse oximetry $\left(\mathrm{SpO}_{2}\right)$, and adverse effects were recorded before and up to $24 \mathrm{~h}$ after drug administration.

Results: There were no significant differences in the preoperative clinical characteristics of the flurbiprofen and control (tramadol) groups. Both flurbiprofen and tramadol significantly alleviated post-thymectomy pain $(p<0.05$ for both), but patients in flurbiprofen group had significantly lower VAS pain scores at $0.5 \mathrm{~h}, 2 \mathrm{~h}, 4 \mathrm{~h}$, and $8 \mathrm{~h}$ after surgery ( $p<0.05$ for all times). There were no significant post-thymectomy changes of heart rate, respiratory rate, mean arterial blood pressure, or $\mathrm{SpO}_{2}$ in either group at all time points.

Conclusions: Post-thymectomy intravenous administration of flurbiprofen axetil provides safe and effective analgesia for MG patients.

Keywords: Myasthenia gravis, Thymectomy, Postoperative care

\section{Background}

Myasthenia gravis (MG) is an autoimmune disorder characterized by progressive muscle fatigue due to alterations of the postsynaptic neuromuscular junction. Most patients also experience abnormalities of the thymus gland, such as thymoma or benign thymus hyperplasia $[1,2]$. Thymectomy in the early stages of MG often improves the overall prognosis $[3,4]$. The extended transsternal thymectomy is believed as a routine and

\footnotetext{
* Correspondence: chenzhenguang@yahoo.com; luohhzm@163.com ${ }^{\dagger}$ Equal contributors

'Department of Thoracic Surgery Lung Cancer Research Center, The First Affiliated Hospital, Sun Yat-sen University, No. 58, Zhongshan Road 2, Guangzhou, Guangdong 510080, People's Republic of China

${ }^{5}$ Department of Cardiothoracic Surgery in Huangpu Division, The First Affiliated Hospital, Sun Yat-sen University, No. 58, Zhongshan Road 2, Guangzhou, Guangdong 510080, People's Republic of China Full list of author information is available at the end of the article
}

complete surgical dissection procedure [5-9], and videoassisted thoracic surgery (VATS) thymectomy and robotic-aided video-assisted thoracoscopic thymectomy are continually being developed $[10,11]$. Based on series of 5-year follow-up data, combined cervical and bilateral videoscopic thymectomy and the combined transcervical-transsternal thymectomy have 51 and 50\%, respectively, remission rates at that interval. Similarly, extended transsternal thymectomy has $40 \%$ remission rate and a high percentage of patients with ocular or mild preoperative MG manifestations [12-14]. It suggests that at the extended or combined transcervical transsternal thymectomy have the better remission rates and the outcomes of different minimally invasive approach are still in the investigative phase. Considering that the extended transsternal thymectomy is conventional until now,

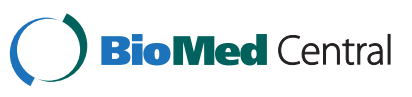


the management of postoperative pain is often a significant problem in MG patients who have undergone thymectomy via median sternotomy incision $[15,16]$. Surgical pain following thymectomy may disrupt breathing and inhibit coughing, and thus may hamper patient recovery and even lead to myasthenic crisis [16,17].

The choice of analgesic agent and route of administration are important because post-thymectomy pain may compromise pulmonary function, and hypersensitivity to an analgesic agent may induce respiratory depression. Previous research reported good results with high thoracic $\left(C_{7} T_{1-3}\right)$ epidural combinations of bupivacaine and morphine in a small number of patients, but the paucity of such cases and the technical difficulties associated with administration of thoracic epidural analgesia have prevented acceptance of this technique [18]. However, there are few established analgesics for treatment of post-thymectomy pain in these patients. Traditional analgesics, such as tramadol, may cause severe nausea and vomiting, and inhibit respiration [19,20]. All analgesics must be used with care in post-thymectomy patients with MG [21].

Non-steroidal anti-inflammatory drugs (NSAIDs) also provide relief from pain after different types of surgery $[22,23]$. Flurbiprofen is an NSAID that can safely and effectively control moderate postoperative pain [23,24]. A recent Cochrane review reported that oral flurbiprofen at a dose of $50 \mathrm{mg}$ or $100 \mathrm{mg}$ provided at least $50 \%$ pain relief in $65 \%$ to $70 \%$ of postoperative patients and only had a weak inhibitory effect on respiration [25]. Systemic flurbiprofen given as treatment for postoperative pain following thoracotomy reduces serum levels of IL-6 and CRP and appears to contribute to the attenuation of the postoperative inflammatory response and prevent postoperative pain [26]. However, the effect of intravenous flurbiprofen on post-thymectomy pain relief in patients with MG has not been established.

In the present study, we investigated the effect of intravenous flurbiprofen on relief from post-thymectomy pain in patients with MG.

\section{Methods}

\section{Patient data}

MG patients who underwent extended thymectomy in the Department of Thoracic Surgery of the First Affiliated Hospital of Sun Yat-sen University (Guangzhou, China) from March 2007 to December 2010 were enrolled. Clinical information was obtained by review of the preoperative and perioperative medical records. MG was diagnosed based on patient history, clinical symptoms, chest computed tomography, positive response to the edrophonium chloride test, and positive findings by single-fiber electromyography and was staged by criteria of the MG Foundation of America [27,28].
Anticholinesterase agents were administered by neurology consultants, and none of the patients received immunosuppressive agents preoperatively. All patients underwent extended thymectomy via median sternotomy followed by standard wound closure, as described previously [29]. Patients were randomly assigned to the flurbiprofen group (50 mg intravenous flurbiprofen axetil diluted in $0.9 \%$ sodium chloride, completed within $1 \mathrm{~h}$ ) or to the control group (100 mg intramuscular tramadol) for postoperative analgesia. The duration of surgery, time of chest drainage, MGFA stage at $72 \mathrm{~h}$ after operation, presence of myasthenia crisis, and adverse reactions were recorded. The hospital ethics committee approved the study protocol (No. 2012-038).

\section{Evaluation of the postoperative pain}

A self-reported visual analog scale (VAS) was used to evaluate postoperative pain, in which 0 indicated "no pain", 1 to 3 indicated "mild pain", 4 to 6 indicated "moderate pain", and 7 to 10 indicated "severe pain". The severity of nausea and vomiting was recorded with a four-point scale in which 0 indicated "no nausea or vomiting", 1 indicated "no nausea at rest or nausea with mild vomiting on exertion", 2 indicated "intermittent nausea at rest or nausea with moderate vomiting on exertion, and 3 indicated "persistent nausea at rest or severe nausea with severe vomiting on exertion". Mean arterial blood pressure, heart rate, respiratory rate, and $\mathrm{SpO}_{2}$, were recorded before surgery and at $0.5 \mathrm{~h}, 2 \mathrm{~h}$, $4 \mathrm{~h}, 8 \mathrm{~h}$, and $24 \mathrm{~h}$ after administration of analgesics. A myasthenic crisis was defined as respiratory failure caused by respiratory muscle weakness. Adverse events, including gastrointestinal bleeding, ulcers, dizziness, lethargy, flushing, itching, urinary retention, constipation, respiratory inhibition, abnormal bleeding, were also recorded. Nausea and vomiting were treated with $10 \mathrm{mg}$ of intramuscular metoclopramide, and headache was treated with $60 \mathrm{mg}$ of intramuscular rotundine.

\section{Statistical analysis}

All statistical calculations were performed using SPSS ver. 14.0 (Chicago, Illinois, USA). All data are given as means \pm standard deviations. The chi-square test and the Mann-Whitney test were used for comparisons, as appropriate. For all tests, a two-sided $p$-value less than 0.05 was considered significant. Hazard ratios (HR) and 95\% confidence intervals (CIs) were calculated to assess the significance of differences.

\section{Results}

\section{Basic clinical information}

Our study cohort consisted of 200 patients with nonthymomatous MG who were treated by extended thymectomy (Table 1). There were 98 males and 102 females, 
Table 1 Clinical and demographic characteristics of the flurbiprofen and control (tramadol) groups

\begin{tabular}{|c|c|c|c|}
\hline Characteristic & Flurbiprofen & Control (tramadol) & $p$ value* \\
\hline$n$ & 110 & 90 & \\
\hline Male/female, $n(\%)$ & $59(53.6) / 51(46.4)$ & $43(47.8) / 47(52.2)$ & 0.504 \\
\hline Age at surgery, years & $31.1 \pm 11.8$ & $30.3 \pm 13.1$ & 0.691 \\
\hline Mean disease duration, years & $1.5 \pm 0.8$ & $1.8 \pm 0.9$ & 0.401 \\
\hline With/without medulla symptoms, $n$ (\%) & $17(15.5) / 93(84.5)$ & $15(16.7) / 75(83.3)$ & 0.816 \\
\hline MGFA stage, $n(\%)$ & & & 0.954 \\
\hline । & $46(41.8)$ & $38(42.2)$ & \\
\hline$\| \mathrm{a}$ & $41(37.3)$ & $33(36.7)$ & \\
\hline$\| \mathrm{b}$ & $17(15.5)$ & $15(16.7)$ & \\
\hline IIla & $6(5.45)$ & $4(4.44)$ & \\
\hline Time of operation (min) & $111.8 \pm 25.4$ & $116.4 \pm 24.0$ & 0.843 \\
\hline Time of chest drainage $(d)$ & $2.7 \pm 0.5$ & $2.4 \pm 0.8$ & 0.927 \\
\hline Myasthenia crisis & $4(3.6)$ & $3(3.3)$ & 0.911 \\
\hline MGFA stage at $72 \mathrm{~h}$ after operation, $n(\%)$ & & & 0.931 \\
\hline । & $47(42.7)$ & $39(43.3)$ & \\
\hline Ila & $42(38.2)$ & $33(36.7)$ & \\
\hline$\| \mathrm{b}$ & 15 (13.6) & $14(15.6)$ & \\
\hline Illa & $6(5.45)$ & $4(4.44)$ & \\
\hline \multicolumn{4}{|l|}{ Adverse reactions } \\
\hline Nausea and vomiting & $14(12.7)$ & $26(28.9)$ & 0.021 \\
\hline Headache & $5(4.5)$ & $9(10.0)$ & 0.162 \\
\hline Facial flushing & $3(2.7)$ & $4(4.4)$ & 0.526 \\
\hline
\end{tabular}

Values are given as median \pm SD or (percentage). MGFA, Myasthenia Gravis Foundation Association.

${ }^{*} p$-values were calculated by the $x^{2}$ test.

the mean age was $30.7 \pm 12.3$ years (range, $15-69$ years; median, 27.2 years), and the mean duration of symptoms was $1.72 \pm 0.21$ years (range, $0.5-23$ years; median, 1 year). A total of 84 patients were MGFA stage I, 74 were stage IIa, 32 were stage IIb, and 10 were stage IIIa.

A total of 110 patients were randomized to the flurbiprofen group and 90 patients to the control (tramadol) group. After surgery, seven cases of myasthenic crisis were recorded, with four cases in the flurbiprofen group (two cases with stage IIb and two cases with stage IIIa), and three cases in the control group (one case with stage IIb and two cases with stage IIIa). Nausea and vomiting were significantly more common in the control group $(28.9 \%$ vs. $12.7 \%$, $p=0.021$ ), but there were no other significant differences between the flurbiprofen and control groups.

\section{Assessment of postoperative pain}

Before analgesic administration, patients in both groups complained of wound pain, difficulty with deep breathing, and coughing, and all patients had VAS pain scores of 7 or higher. Our results indicate that both drugs significantly alleviated postoperative pain and that the mean VAS pain score was significantly lower in the flurbiprofen group at $0.5 \mathrm{~h}, 2 \mathrm{~h}, 4 \mathrm{~h}$, and $8 \mathrm{~h}$ after surgery $(p<0.05)$ (Figure 1$)$. There were no differences between the two groups in heart rate (Figure 2A), respiratory rate (Figure 2B), mean arterial blood pressure (Figure 2C), or oxygen saturation (Figure 2D) for up to $24 \mathrm{~h}$ after surgery.

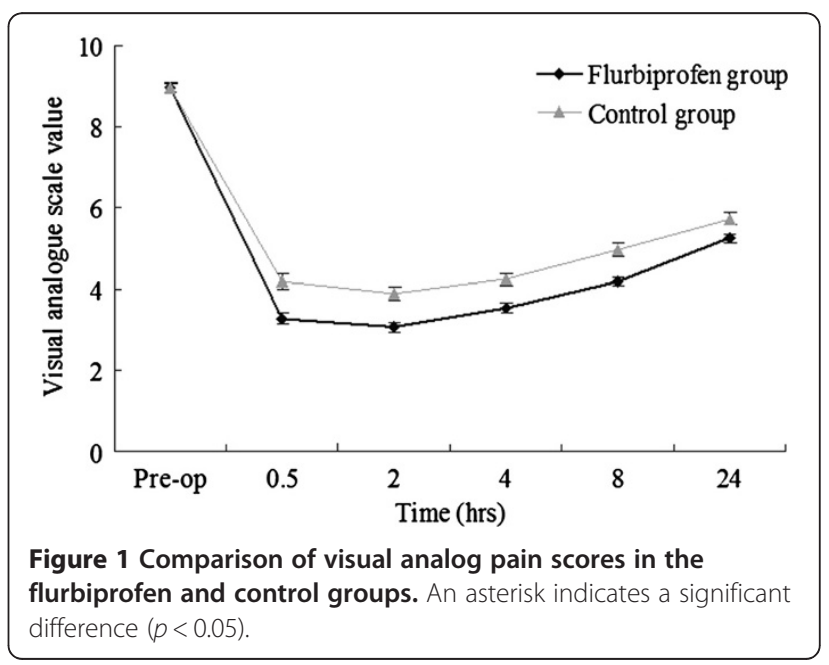



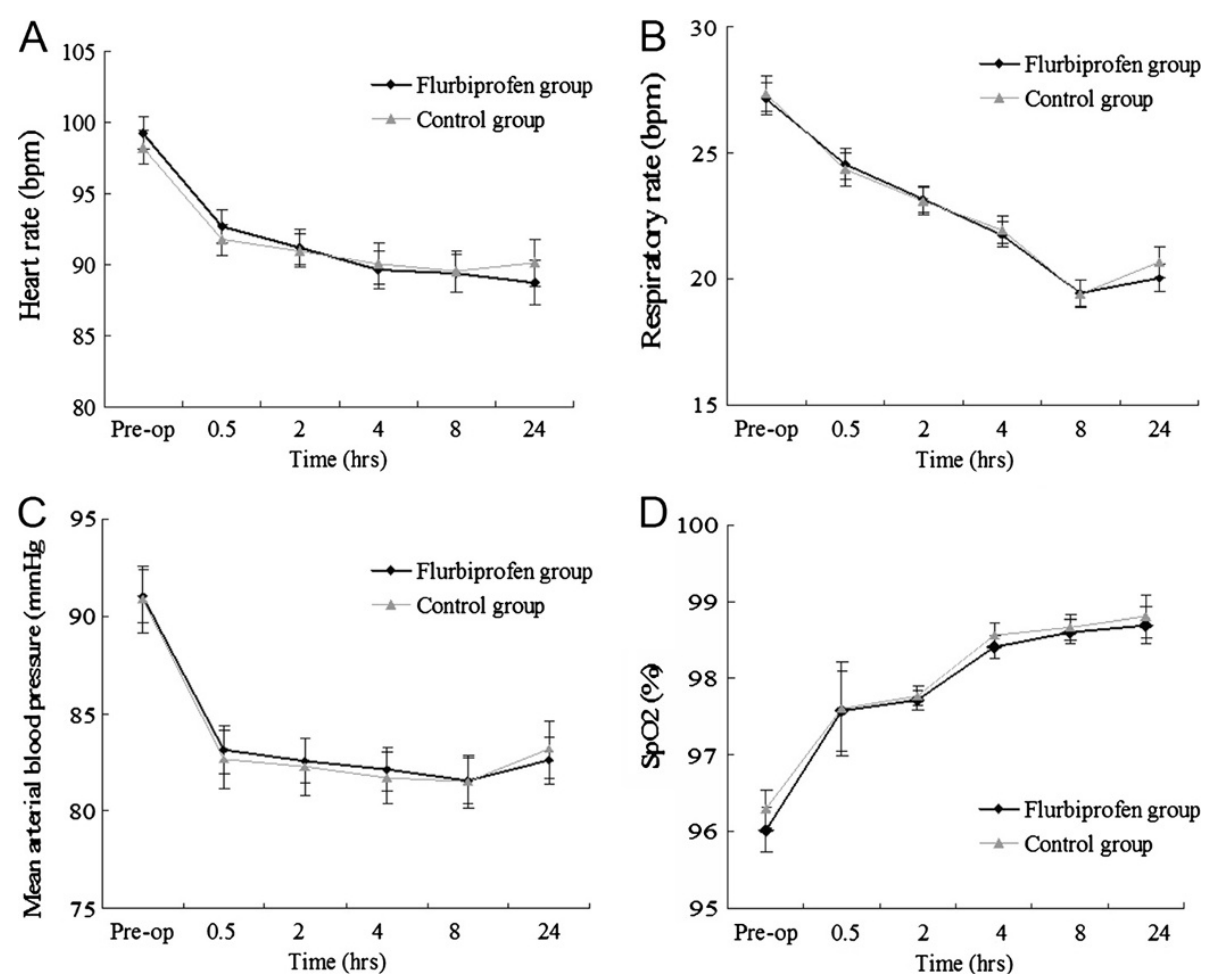

Figure $2 \mathrm{~A}$, Comparison of heart beat variation in the flurbiprofen and control groups; B, Comparison of respiratory rate variation in the flurbiprofen and control groups; C, Comparison of mean arterial blood pressure variation in the flurbiprofen and control groups; D, Comparison of variation in blood oxygen saturation in the flurbiprofen and control groups.

\section{Adverse reactions}

Nausea and vomiting were significantly more common in the control group than in the flurbiprofen group (12.7\% vs. $28.9 \%, p=0.021$, Table 1$)$. At $30 \mathrm{~min}$ after initiation of analgesia, there were no adverse reactions in either group. In the flurbiprofen group, there 14 cases of nausea and vomiting at $2 \mathrm{~h}$, (6 cases with scores of 3,8 cases with scores of 2), 9 cases of nausea and vomiting at $4 \mathrm{~h}$, and 5 cases of nausea and vomiting at $8 \mathrm{~h}$. In the control group, there were 26 cases of nausea and vomiting at $2 \mathrm{~h}$ (12 cases with scores of 3,14 cases with scores of 2), and 16 cases of nausea and vomiting at $4 \mathrm{~h}$ and $8 \mathrm{~h}$.

At $2 \mathrm{~h}$ after drug injection, five cases in flurbiprofen group and nine cases in control group had headaches, but all of these patients experienced remission at $4 \mathrm{~h}$. Remarkably, three cases in the flurbiprofen group and four cases in the control (tramadol) group had facial flushing at $2 \mathrm{~h}$ after drug injection, and these symptoms remained for $24 \mathrm{~h}$ in all patients.

\section{Discussion}

Extended thymectomy is recognized worldwide as an important technique to manage myasthenia gravis, and median sternotomy is the major surgical method [1,3,27]. The injury caused by this surgery is considerable, because the pleura are often damaged during resection of anterior mediastinal fat tissue. Surgery may lead to hemothorax or pleural effusion that can affect pulmonary re-expansion. Coughing, sputum expulsion, and initiation of deep breathing are important measures that promote lung re-expansion and reduce the risk of pulmonary infection. The surgical pain of such patients typically has medium-to-high intensity, and may inhibit breathing, coughing, and sputum expulsion, thereby disrupting postoperative recovery, increasing the risk of pulmonary atelectasis and infection, and even induce myasthenic crisis [30]. Our previous study of MG patients demonstrated that the serum concentration of immunoglobulin $\mathrm{G}$ was high after thymectomy [31]. Another report showed that the levels of serum CRP, IL-6, and TNF- $\alpha$ were elevated after thoracotomy [26]. Together, these findings indicate significant inflammation after thymectomy, suggesting that an anti-inflammatory agent such as flurbiprofen may be effective in reducing this inflammation.

Common analgesics, such as tramadol and adolens, are often not recommended for MG patients because they can depress respiration and are associated adverse effects (nausea, vomiting, irritability) that can increase the risk of a myasthenic crisis or worsen postoperative conditions. Therefore, an effective analgesic is needed that 
allows pain-free recovery from thymectomy but does not inhibit the respiratory muscles.

Flurbiprofen axetil (2-[3-fluoro-4-biphenyl] propanoic acid) is an NSAID of the propionic acid class and tablets are approved for relief of pain from rheumatoid arthritis and osteoarthritis [32]. Intravenous flurbiprofen axetil is provided as $50 \mathrm{mg}$ ampoules and selectively accumulates at the surgical incision and inflammation sites after administration. Flurbiprofen axetil is mostly metabolized into flurbiprofen by hydrolysis and its analgesic effect is believed to result from the reversible inhibition of cyclooxygenase and peripheral inhibition of prostaglandin synthesis. Analgesia has been reported to last for up to $24 \mathrm{~h}$ after intravenous administration [33]. During postoperative pain management with flurbiprofen, patients must be monitored for side effects, especially gastrointestinal effects, as with all NSAIDs $[2,34]$. Previous studies have reported that use of flurbiprofen for postoperative analgesia in anesthesia, general surgery, obstetrics and gynecology, and orthopedics was effective and safe, had little effect on respiration, and prolonged the duration of analgesia [35-38]. However, there have been no reports on the use of flurbiprofen following thoracic surgery or in patients with MG following extended thymectomy.

Our results indicate that intravenous flurbiprofen axetil can effectively reduce post-thymectomy pain without disruption of respiratory rate, heart rate, or blood pressure. The analgesic effect lasted for up to $24 \mathrm{~h}$ for most patients. There was no significant difference in the incidence of myasthenic crisis in the flurbiprofen and control groups and there were fewer adverse effects in the flurbiprofen group. The most common adverse effects following flurbiprofen axetil were headache, vomiting, and flushing. Mild symptoms resolved by themselves within 3 days, and there were more cases of adverse reactions in the control group. Slow intravenous administration of flurbiprofen allows immediate withdrawal if respiratory inhibition occurs and provides an extended duration of analgesia.

This study confirms that flurbiprofen axetil is a safe and effective analgesic for post-thymectomy patients with MG and that it is associated with a lower incidence of adverse reactions than tramadol. Thus, slow intravenous administration of flurbiprofen axetil is safe for clinical use and is not associated with respiratory inhibition.

\section{Competing interests}

The authors declare no competing interests.

\section{Authors' contributions}

CS and ZC designed the study, collected data, and drafted the manuscript. CC performed the statistical analysis and drafted the manuscript. YS, YL, JZ, BZ participated in data collection. HL participated in the study design and coordination and helped to draft the manuscript. All authors read and approved the final manuscript.

\section{Author details}

'Department of Thoracic Surgery Lung Cancer Research Center, The First Affiliated Hospital, Sun Yat-sen University, No. 58, Zhongshan Road 2, Guangzhou, Guangdong 510080, People's Republic of China. ${ }^{2}$ Department of Ophthalmology, The First Affiliated Hospital, Sun Yat-sen University, Guangzhou, Guangdong 510080, People's Republic of China. ${ }^{3}$ Department of Anesthesiology, The First Affiliated Hospital, Sun Yat-sen University, Guangzhou, Guangdong 510080, People's Republic of China. ${ }^{4}$ Department of Neurology, The First Affiliated Hospital, Sun Yat-sen University, Guangzhou, Guangdong 510080, People's Republic of China. ${ }^{5}$ Department of Cardiothoracic Surgery in Huangpu Division, The First Affiliated Hospital, Sun Yat-sen University, No. 58, Zhongshan Road 2, Guangzhou, Guangdong 510080, People's Republic of China.

Received: 9 February 2012 Accepted: 23 September 2012 Published: 29 September 2012

\section{References}

1. Drachman DB: Myasthenia gravis. N Engl J Med 1994, 330:1797-1810.

2. Hughes BW, Moro De Casillas ML, Kaminski HJ: Pathophysiology of myasthenia gravis. Semin Neurol 2004, 24:21-30.

3. Masaoka A: Extended trans-sternal thymectomy for myasthenia gravis. Chest Surg Clin N Am 2001, 11:369-387.

4. Oosterhuis HJ: Thymectomy in myasthenia gravis. A review. Ital J Neurol Sci 1983, 4:399-407.

5. Nussbaum MS, Rosenthal GJ, Samaha FJ, Grinvalsky HT, Quinlan JG, Schmerler M, Fischer JE: Management of myasthenia gravis by extended thymectomy with anterior mediastinal dissection. Surgery 1992, 112:681-688.

6. Frist WH, Thirumalai S, Doehring CB, Merrill WH, Stewart JR, Fenichel GM, Bender HW Jr: Thymectomy for the myasthenia gravis patient: factors influencing outcome. Ann Thor Surg 1994, 57:334-338.

7. Fujii N, Itoyama Y, Machi M, Goto I: Analysis of prognostic factors in thymectomized patients with myasthenia gravis: correlation between thymic lymphoid cell subsets and postoperative clinical course. J Neurol Sci 1991, 105(2):143-149.

8. Masaoka A, Yamakawa Y, Niwa H, Fukai I, Condo S, Kobayashi M, Fujii Y, Monden Y: Extended thymectomy for myasthenia gravis: a 20 year review. Ann Thor Surg 1996, 62:853-859. Sept.

9. Detterbeck FC, Scott WW, Howard JF, Egan TM, Keagy BA, Starek JK, Mill MR, Wilcox BR: One hundred consecutive thymectomies for myasthenia gravis. Ann Thorac Surg 1996, 62:242-245.

10. Mack MJ, Scruggs GR: Video-assisted thymectomy. In General thoracic surgery. 5th edition. Edited by Shields T, LoCicero J, Ponn R. Philadelphia, PA: Lippincott Williams \& Wilkins; 2000:2243-2249. 2 Section XXVIII, Chapter 173.

11. Mineo TC, Pompeo E, Ambrogi V, Sabato AF, Bernardi G, Casciani CU: Adjuvant pneumomediastinum in thoracoscopic thymectomy for myasthenia gravis. Ann Thor Surg 1996, 62:1210-1212.

12. Shrager JB, Deeb ME, Mick R, Brinster CJ, Childers HE, Marshall MB, Kucharczuk JC, Galetta SL, Bird SJ, Kaiser LR: Transcervical thymectomy for myasthenia gravis achieves results comparable to thymectomy by sternotomy. Ann Thorac Surg 2002, 74:320-327.

13. Lindberg C, Andersen O, Larsson S, Oden A: Remission rate after thymectomy in myasthenia gravis when the bias of immunosuppressive therapy is eliminated. Acta Neurol Scand 1992, 86(3):323-328.

14. Jaretzki A III, Penn AS, Younger DS, Wolff M, Olarte MR, Lovelace RE, Rowland LP: "Maximal" thymectomy for myasthenia gravis: results. J Thorac Cardiovasc Surg 1988, 95:747-757.

15. Kalso E, Mennander S, Tasmuth T, Nilsson E: Chronic post-sternotomy pain. Acta Anaesthesiol Scand 2001, 45:935-939.

16. Meyerson J, Thelin S, Gordh T, Karlsten R: The incidence of chronic post-sternotomy pain after cardiac surgery-a prospective study. Acta Anaesthesiol Scand 2001, 45:940-944.

17. Abel M, Eisenkraft JB: Anesthetic implications of myasthenia gravis. Mt Sinai J Med 2002, 69:31-37.

18. Ferreti F, Crestan IS, Rudriguez NJ, Tosi C, Martinoli S: Can one use high thoracic epidural analgesia in post operative intensive care of the myasthenia patient following trans sternal thymectomy? Schweiz Med Woehenschr 1987, 117:438-441. 
19. Nilsson E, Perttunen K, Kalso E: Intrathecal morphine for post-sternotomy pain in patients with myasthenia gravis: effects on respiratory function. Acta Anaesthesiol Scand 1997, 41:549-556.

20. Hopkins D, Shipton EA, Potgieter D, CA VdM, Boon J, De Wet C, Murphy J: Comparison of tramadol and morphine via subcutaneous PCA following major orthopaedic surgery. Can J Anaesth 1998, 45:435-442.

21. Haroutiunian S, Lecht S, Zur AA, Hoffman A, Davidson E: The challenge of pain management in patients with myasthenia gravis. J Pain Palliat Care Pharmacother 2009, 23:242-260.

22. Perttunen $\mathrm{K}$, Nilsson $\mathrm{E}$, Kalso E: I.v. diclofenac and ketorolac for pain after thoracoscopic surgery. Br J Anaesth 1999, 82:221-227.

23. Tarkkila P, Saarnivaara L: Ketoprofen, diclofenac or ketorolac for pain after tonsillectomy in adults? Br J Anaesth 1999, 82:56-60.

24. Mikawa K, Nishina K, Maekawa N, Shiga M, Obara H: Dose-response of flurbiprofen on postoperative pain and emesis after paediatric strabismus surgery. Can J Anaesth 1997, 44:95-98.

25. Ottinger ML, Kinney KW, Black JR, Wittenberg M: Comparison of flurbiprofen and acetaminophen with codeine in postoperative foot pain. J Am Podiatr Med Assoc 1990, 80:266-270.

26. Esme $H$, Kesli R, Apiliogullari B, Duran FM, Yoldas B: Effects of flurbiprofen on CRP, TNF-a, IL-6, and postoperative pain of thoracotomy. Int J Med Sci 2011, 8:216-221.

27. Budde JM, Morris CD, Gal AA, Manosur KA, Miller Jl: Predictor of outcome in thymectomy for myasthenia gravis. Ann Thorac Surg 2001, 72:197-202.

28. Osserman KE: Myasthenia gravis. Grune and Stratton: New York; 1958.

29. Bulkley GB, Bass KN, Stephenson GR, Diener-West M, George S, Reilly PA, Baker RR, Drachman DB: Extended cervicomediastinal thymectomy in the integrated management of myasthenia gravis. Ann Surg 1997, 226:324-335.

30. Massard G, Wihlm JM: Postoperative atelectasis. Chest Surg Clin N Am 1998, 8:503-528. viii.

31. Chen ZG, Luo HH, Peng YW, Cai LE, Zhang JL, Su CH, Zou JY: Comparative clinical features and immune responses after extended thymectomy for myasthenia gravis in patients with atrophic versus hyperplastic thymus. Ann Thorac Surg 2011, 91:212-218.

32. Lomen PL, Samal BA, Lamborn KR, Sattler LP, Crampton SL: Flurbiprofen for the treatment of bone pain in patients with metastatic breast cancer. Am J Med 1986, 80(3A):83-87.

33. Sultan A, MCQuay HJ, Moore RA, Derry S: Single dose oral flurbiprofen for acute postoperative pain in adults. Cochrane Database of Systematic Reviews 2009, (3). doi:0.1002/14651858.CD007358.pub2. Art. No.: CD007358.

34. Roszkowski MT, Swift JQ, Hargreaves KM: Effect of NSAID administration on tissue levels of immunoreactive prostaglandin E2, leukotriene B4, and (S)-flurbiprofen following extraction of impacted third molars. Pain 1997, 73:339-345

35. Swift JQ, Garry MG, Roszkowski MT, Hargreaves KM: Effect of flurbiprofen on tissue levels of immunoreactive bradykinin and acute postoperative pain. J Oral Maxillofac Surg 1993, 51:112-116.

36. Troullos ES, Hargreaves KM, Butler DP, Dionne RA: Comparison of nonsteroidal anti-inflammatory drugs, ibuprofen and flurbiprofen, with methylprednisolone and placebo for acute pain, swelling, and trismus. J Oral Maxillofac Surg 1990, 48:945-952.

37. Sisk AL, Bonnington GJ: Evaluation of methylprednisolone and flurbiprofen for inhibition of the postoperative inflammatory response. Oral Surg Oral Med Oral Pathol 1985, 60:137-145.

38. Dionne RA, Wirdzek PR, Fox PC, Dubner R: Suppression of postoperative pain by the combination of a nonsteroidal anti-inflammatory drug, flurbiprofen, and a long-acting local anesthetic, etidocaine. J Am Dent Assoc 1984, 108:598-601.

\section{Submit your next manuscript to BioMed Central and take full advantage of:}

- Convenient online submission

- Thorough peer review

- No space constraints or color figure charges

- Immediate publication on acceptance

- Inclusion in PubMed, CAS, Scopus and Google Scholar

- Research which is freely available for redistribution 